\title{
CAPILLARY PUMPED LOOP AS A TOOL FOR COLLECTING LARGE HEAT FLUXES FROM ELECTRONIC DEVICES ON WARSHIPS
}

\author{
Dariusz Mikielewicz, Prof. \\ Paweł Szymański, PhD \\ Gdańsk University of Technology, Poland
}

\begin{abstract}
The combat potential of future warships will be directly related to the use of modern electronic devices being parts of advanced systems, such as, for instance, radar systems, fire aiming systems, fire detection systems, electric drive systems, and even electronic and radio-electronic weaponry, railguns and lasers, installed on these warships. The capacity and functionality of these devices is continually increasing, at decreasing mass and dimensions, which results in higher power consumption. Heat collection becomes a growing problem in operation of these devices.

The paper presents a concept of the use of the CPL (Capillary Pumped Loop) cycle for passive heat collection from precise electronic devices used on warships. It also includes the description of the experimental rig and discussion of the results of laboratory tests performed on this rig and confirmed using the mathematical model developed by the authors.
\end{abstract}

Keywords: Loop Heat Pipe, Capillary Pumped Loop, Porous Media, Multiphase Flow, Heat Transfer

\section{INTRODUCTION}

The majority of electronic systems which are presently used on warships and whose correct operation is essential for the operation and performance of the whole ship, (radiocommunication systems, for instance) require special heat collection methods and devices. Those systems generate large amounts of heat and should be cooled using devices which are, at the same time, highly efficient and reliable, do not emit electromagnetic disturbances, and are maintenance-free and able to operate in harsh environmental conditions.

To meet the challenge of designing such heat collection devices, an experimental rig was built in the Engineering Testing Laboratory, Gdansk University of Technology, and a series of experimental tests were performed on the CPL (Capillary Pumped Loop) cycle.

The CPL concept was developed in NASA laboratories in the 1960's, bur real progress in studies upon CPL started twenty years later, as a response to large demand for space technologies. At that time, NASA employed American scientists and research companies to start designing and testing highly efficient heat transfer devices which would be resistant to orientation changes in the gravity field and able to operate in harsh conditions. An introductory overview of this subject has been given in earlier articles by the authors [1-3].

The CPL cycle is a passive two-phase heat transfer device in which the flow of liquid is generated by capillary forces created in the evaporator (this is the basic advantage of this 
Nomenclature

$$
\begin{aligned}
& A \text { - cross-section area; }\left[\mathrm{m}^{2}\right] \\
& C_{p} \text {-specific heat at constant pressure; }\left[\frac{\mathrm{J}}{\mathrm{kg} \cdot \mathrm{K}}\right] \\
& D \text { - diameter; }[\mathrm{m}] \\
& h_{l v} \text { - heat of vaporization of the working fluid; }\left[\frac{\mathrm{kJ}}{\mathrm{kg}}\right] \\
& k_{\text {eff }} \text { - effective thermal conductivity coefficient in the wick; }\left[\frac{\mathrm{W}}{\mathrm{m} \cdot \mathrm{K}}\right] \\
& L \text { - length; }[\mathrm{m}] \\
& \dot{m} \text { - mass flow rate; }\left[\frac{\mathrm{kg}}{\mathrm{s}}\right] \\
& \dot{Q} \text { - heat flux; }[\mathrm{W}] \\
& T \text { - temperature; }\left[{ }^{\circ} \mathrm{C}\right] \\
& U \text { - thermal transmittance; }\left[\frac{\mathrm{W}}{\mathrm{m}^{2} \cdot \mathrm{K}}\right]
\end{aligned}
$$

solution, as it does not need pumping work and does not consume electric energy). The evaporator is filled with porous wick material, which is responsible for capillary transport of fluid in the system

The classical CPL consists of the evaporator and the condenser, connected with each other by a system of liquid and vapour transport lines, and the compensation reservoir. The capillary pumping cycle is schematically shown in Fig. 1. Compared to similar two-phase heat transport devices, such as the LHP (Loop Heat Pipe) for instance, CPL has much wider ability to adjust and control the operating temperature in the system. This ability is ensured by the presence of the compensation reservoir in the system, which is situated at a relatively large distance from the evaporator and beyond the working fluid flow loop. As a result, the fluid returning from the condenser to the evaporator does not flow directly through this reservoir [4]. The compensation reservoir is filled with the working fluid in two-phase state, and remains in the saturation state during system operation. By controlling the temperature in the compensation reservoir we control the operating temperature of the CPL (for instance, the saturation temperature in the evaporator wick) [5]. Due to this wide ability to adjust and control the operating temperature, CPL systems have become frequently used for heat collection in numerous heavilv thermallv loaded precise electronic

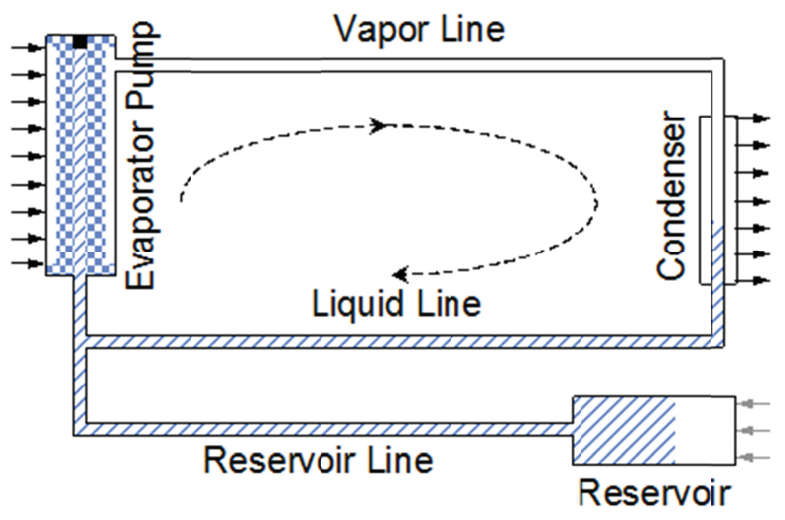

Fig. 1 Typical single-evaporator $C P L$

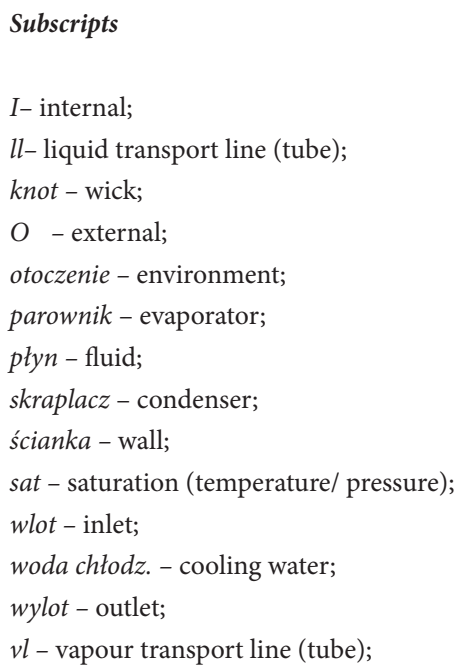

devices, and not only in space industry [6-9]. Separating the compensation reservoir from the remaining part of the system makes the CPL more tolerant to heat loss, which facilitates its installation. Detailed descriptions of CPL systems can be found in [10-11], for instance.

\section{EXPERIMENTAL RIG}

The experimental rig for examining passive heat collection from precise electronic devices which has been built at the Gdansk University of Technology, Faculty of Mechanical Engineering, Department of Energy and Industrial Apparatus, is capable of collecting thermal power of up to $100 \mathrm{~W}$ (which is approximately the amount of heat generated by a mediumpower radio communication device) and transport it over a distance of about $0,5 \mathrm{~m}$.

The basic component of the capillary pumping cycle is the evaporator filled with porous wick material. This evaporator, playing the role of heat collector, makes use of the phenomenon of capillary pressure generated in the porous medium, with the resultant flow of fluid moistening the wick surface. Within the framework of the here reported research, two evaporators filled with different porous wick materials were tested.

Evaporator 1 consisted of a cylindrical tube filled with porous wick material based on nickel powders with aluminium admixture. This material is fully permeable, the diameter of its pores is $5 \mu \mathrm{m}$, and its total porosity is equal to $55 \%$. Evaporator 2, in turn, was filled with porous wick material based on nickel powders with cuprum admixture. This material is also fully permeable, the diameter of its pores is $5 \mu \mathrm{m}$ and total porosity is equal to $60 \%$. The structure of both evaporators is the same: each evaporator has 10 vapour tubes, of $1,7 \mathrm{~mm}$ in diameter, drilled in the porous material just below the evaporator casing surface. Geometrical dimensions of the evaporators are shown in Fig. 2, and their external appearance in Fig. 3. 


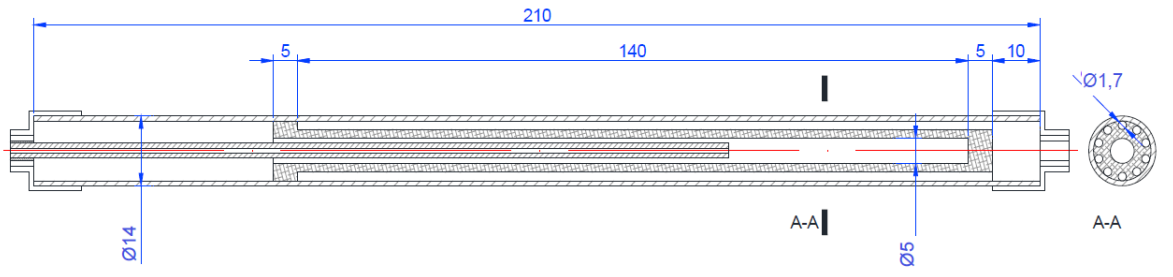

Fig. 2. Dimensions of the evaporator with porous wick material

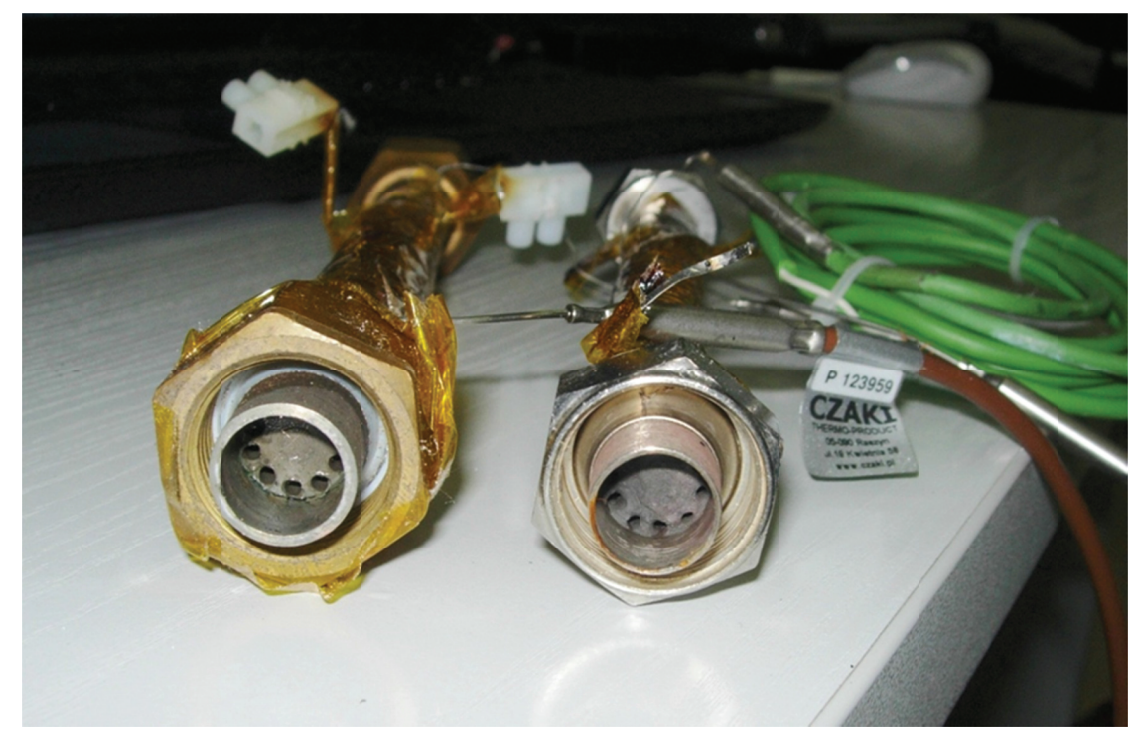

Fig. 3. Evaporators with porous wick materials: $\mathrm{Ni}-\mathrm{Cu}$ (left) and $\mathrm{Ni}-\mathrm{Al}$ (right)

The casings of both evaporators are made of stainless steel, and their walls are $1 \mathrm{~mm}$ thick. This material was selected to provide opportunities for examining various fluids, by eliminating possible damage (corrosion) of the casing in tests performed in the environment of incompatible fluids. In the here reported tests the attention was focused on two working fluids, which were water and acetone.
Generally, the CPL cycle element which is most important and most difficult to design is the compensation reservoir. This element is responsible for hydrodynamic control of the system, as well as for the adjustment and control of its operating temperature and pressure. The compensation reservoir should be designed in such a way that, at the maximum operating temperature of the tube with the working loop, it will be able to compensate thermal expansion of the working fluid (from the operating conditions corresponding to the lowest temperature, up to the harshest conditions and highest temperature). Here, the overall dimensions of the compensation reservoir have been selected experimentally using the trial-and-error method. The reservoir was connected with the CPL system by a tube of $3,87 \mathrm{~mm}$ in internal diameter. The scheme of the research rig used for examining CPL cycles with selected evaporators is given in Fig. 4, and the real appearance (photo) of the installation prior to its insulation is shown in Fig. 5

Liquid and vapour transport tubes are made of acid-resistant stainless steel. They are $3,87 \mathrm{~mm}$ in internal diameter and $50 \mathrm{~mm}$ long. The condenser section is a typical shelland-tube heat exchanger of double-pipe type in which the liquid and vapour transport lines are round tubes of $3,87 \mathrm{~mm}$ in diameter and $1,24 \mathrm{~mm}$ thick. The condenser was cooled by a water jacket supplied from the water-pipe 


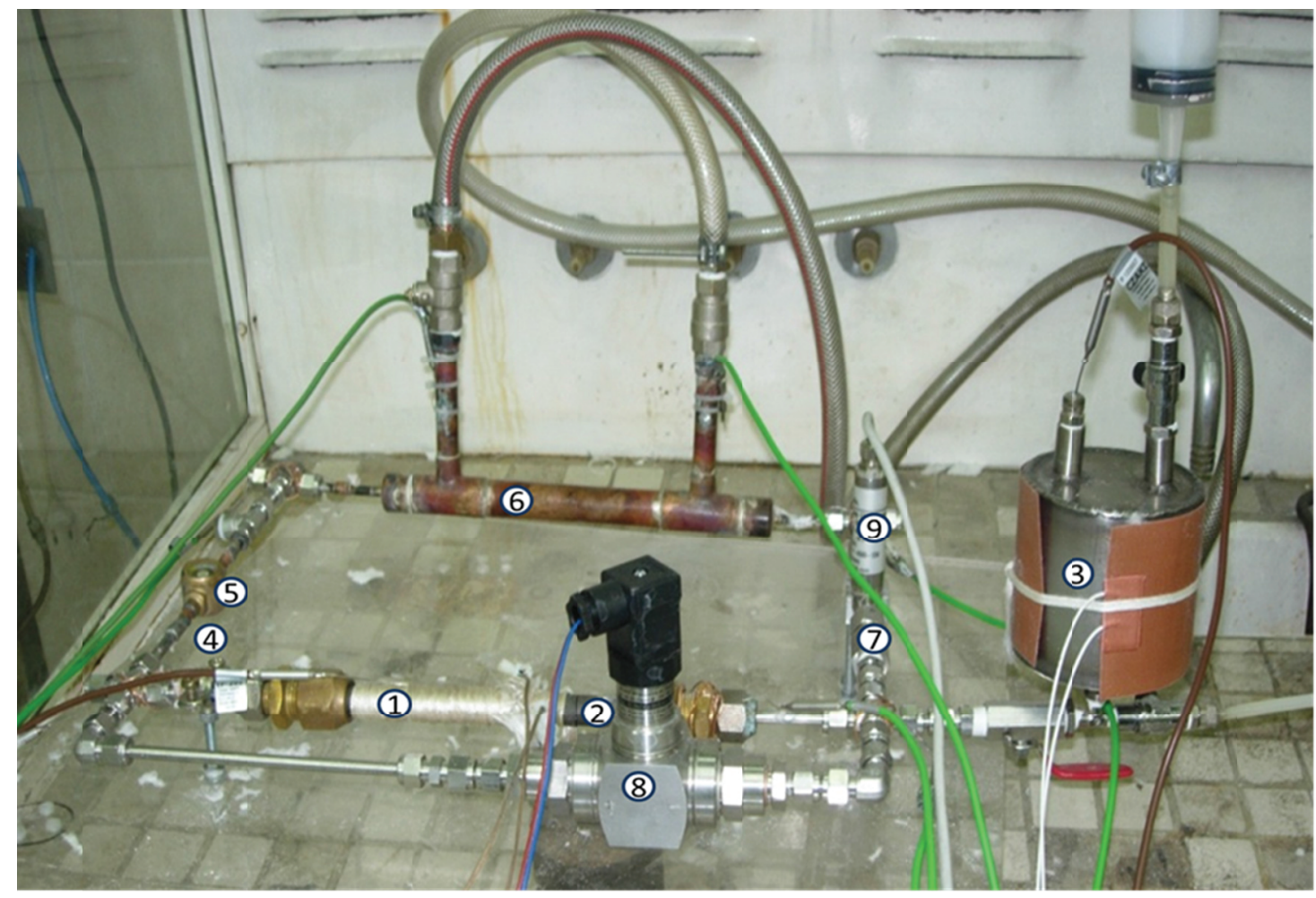

Fig. 5. General view of the installation for examining CPL evaporators with porous wick materials (prior to placing external insulation). 1-Evaporator, 2-Compensation chamber, 3-Compensation, reservoir, 4-Vapour transport line, 5-Visualisation window, 6-Condenser, 7-Liquid transport line, 8-Differential pressure transducer, 9-Pressure transducer.

network, and the cooling water flow rate was controlled using a rotameter.

The heat source which generated the temperature difference in the vicinity of the wick and, as a further consequence, initiated the effect of capillary pumping, was a $100 \mathrm{~W}$ resistive heating element installed on the evaporator casing. The heater was fed from a laboratory DC power supply with controlled output voltage and current.

Another heat source needed for making the CPL operate was a resistive heater installed on the compensation reservoir. For this purpose a 300W elastic silicone heating mat produced by Watlow was used. The mat was fed from a laboratory DC power supply with controlled output voltage and current. The advantage and characteristic feature of the electric heating mat is its easy forming into arbitrary shapes, which ensures good adaptation to the heated surface and, consequently, better thermal contact. The heating mat was used for longlasting heating and keeping a constant temperature in the condensation reservoir.

Thermodynamic and electric quantities which were measured on the test rig during examination of evaporators with porous wick materials were the following:

a) absolute pressure in the system - measured by the pressure transducer installed on the liquid transport line.

b) pressure difference between points in front of and behind the evaporator - measured by the differential pressure transducer connected to the system via tubes of $3,87 \mathrm{~mm}$ in diameter. Pressure difference measurement is one of most significant measurements in the here reported experiment.

c) temperature - for this purpose a set of 10 T-type thermocouples was used. The measuring range of the thermocouples was from $-200^{\circ} \mathrm{C}$ to $+350^{\circ} \mathrm{C}$, while their sensitivity was $30 \mu \mathrm{V} / \mathrm{K}$. They were distributed in such a way as to be able to measure temperatures at key points of the research rig.

d) electric power - measured using a laboratory DC power supply with controlled output voltage and current.

e) cooling water flow rate - measured by a rotameter installed at cooling water inlet.

\section{CALCULTIONS}

The performance and operating parameters of the capillary pumped loop are assessed based on the mass flow rate of the working liquid and the heat balance of the CPL installation.

\section{DETERMINING THE MASS FLOW RATE OF THE LIQUID IN THE CPL INSTALLATION}

The information on the flow rate of the liquid inside the installation is essential when assessing the CPL performance and calculating the balance heat. In the here examined case of a single heat tube, direct measurement of this quantity is extremely difficult, therefore is was indirectly determined, for steady-state conditions, from the heat balance calculated for 
the known values of the heat flux delivered to the evaporator and the temperatures at key points. The mass flow rate was calculated as the ratio of the heat flux delivered to the evaporator and the heat of evaporation of the liquid in the evaporator:

$$
\dot{m}=\frac{\dot{Q}_{\text {parownika }}}{h_{l v}}
$$

\section{CPL HEAT BALANCE}

Calculating the heat balance for the CPL installation aims at assessing: losses (or gains) of the heat delivered to the installation, losses (or gains) of the heat passed to the environment, and the heat transfer between particular installation components. In the present case, the heat balance was calculated using an in-house mathematical model being a modification of the model proposed by Kay and Hoang [12]. To calculate the heat balance for an installation we need such data as: basic parameters of structural components of the installation, the type and parameters of the working fluid (at a given measuring point), the mass flow rate of the working fluid, working fluid temperatures at key points of the installation, the saturation pressure and temperature of the fluid in the installation, heat transfer coefficients, the mass flow rate and temperature of the cooling water in the condenser, and the power delivered to the system.

The heat balance was calculated assuming that the working medium in the installation is in a single-phase state, i.e. either liquid or vapour.

During the steady-state CPL operation the following condition is to be met:

$$
\dot{Q}_{\text {parownik }}=\dot{Q}_{\text {skraplacz }}
$$

The amount of heat delivered to the evaporator was determined by measuring the electric power consumed by the heater, while the heat collected by the condenser was calculated from the cooling water heat balance.

$$
\dot{Q}_{\text {skraplacz }}=\dot{m}_{\text {wodychlodz }} C_{p}\left(T_{\text {wylot wchlodz }}-T_{\text {wlotwchlodz }}\right)
$$

The heat penetrating through the evaporator casing wall was calculated as:

$$
\dot{Q}_{\text {scianka-knot }}=\frac{U \cdot A}{L}\left(T_{\text {scianki }}-T_{\text {sat }}\right)
$$

while the heat flux penetrating through the wick was calculated from the formula:

$$
\dot{Q}_{k n o t-p l y n}=\frac{2 \pi k_{e f f} L_{k n o t}}{\ln \left(\frac{D_{O k n o t}}{D_{I k n o t}}\right)} \Delta T_{k n o t}
$$

where $\Delta T_{k n o t}$ is the temperature difference in the wick.
The next step in calculating the heat balance for the CPL installation was assessing the heat loss to (or gain from) the environment in the liquid and vapour transport lines.

These values were calculated using the following formulas: - $\quad$ for the liquid transport line:

$$
\dot{Q}_{l l-o t o c z e n i e}=\dot{m} c_{p}\left(T_{l l w l o t}-T_{l l w y l o t}\right)
$$

- for the vapour transport line

$$
\dot{Q}_{\text {vlotoczenie }}=\dot{m} c_{p}\left(T_{v l \text { wylot }}-T_{v l \text { wlot }}\right)
$$

\section{RESULTS OF EXPERIMENTAL CPL TESTS}

The experimental tests were performed using two evaporators and two different working media, at different thermal loads. To calculate the heat balance for the entire installation, the effect of the delivered heat flux on the temperature increase in the installation was firstly examined.

The first series of tests referred to the CPL system with the evaporator filled with porous $\mathrm{Ni}-\mathrm{Cu}$ wick material. The working medium in the installation was water.

One measuring session in these tests lasted 12 hours. During the initial 3 hours the installation was prepared (heated) to reach the steady state and constant temperature. After this time, the temperature in the compensation reservoir was approximately equal to $120^{\circ} \mathrm{C}$. Once the steady state of system operation was reached, the evaporator started to be heated by a small-power heater of $20 \mathrm{~W}$ power capacity. It is noteworthy that the temperature at condenser outlet slightly decreased after switching the cooling water flow on. This temperature decrease was caused by cooling the liquid transport line inlet as a result of conductive heat transfer between the condenser and the liquid transport tube. The analysis of temperature distribution as function of the delivered heat flux, for water as working medium and the evaporator filled with porous $\mathrm{Ni}-\mathrm{Cu}$ wick material is shown in Fig. 6.

The absolute pressure in the system was measured using the pressure transducer installed on the liquid transport line. This pressure was approximately equal to 3,24 bar and remained unchanged during system operation (i.e. from the time when the CPL start-up was observed). In the loop the saturation state was reached, for the given pressure and the corresponding temperature equal to $136,2^{\circ} \mathrm{C}$.

The start-up of the installation (i.e. the flow of the working medium) was confirmed by flow observation in the visualisation (inspection) window installed on the vapour transport line, and by measuring pressure difference in front of and behind the evaporator. Another way to detect the installation start-up was observing the temperature increase in the vapour transport line.

With time, the temperature in the vapour transport line also became steady and approximately equal to $115^{\circ} \mathrm{C}$. This temperature was measured using a thermocouple installed 


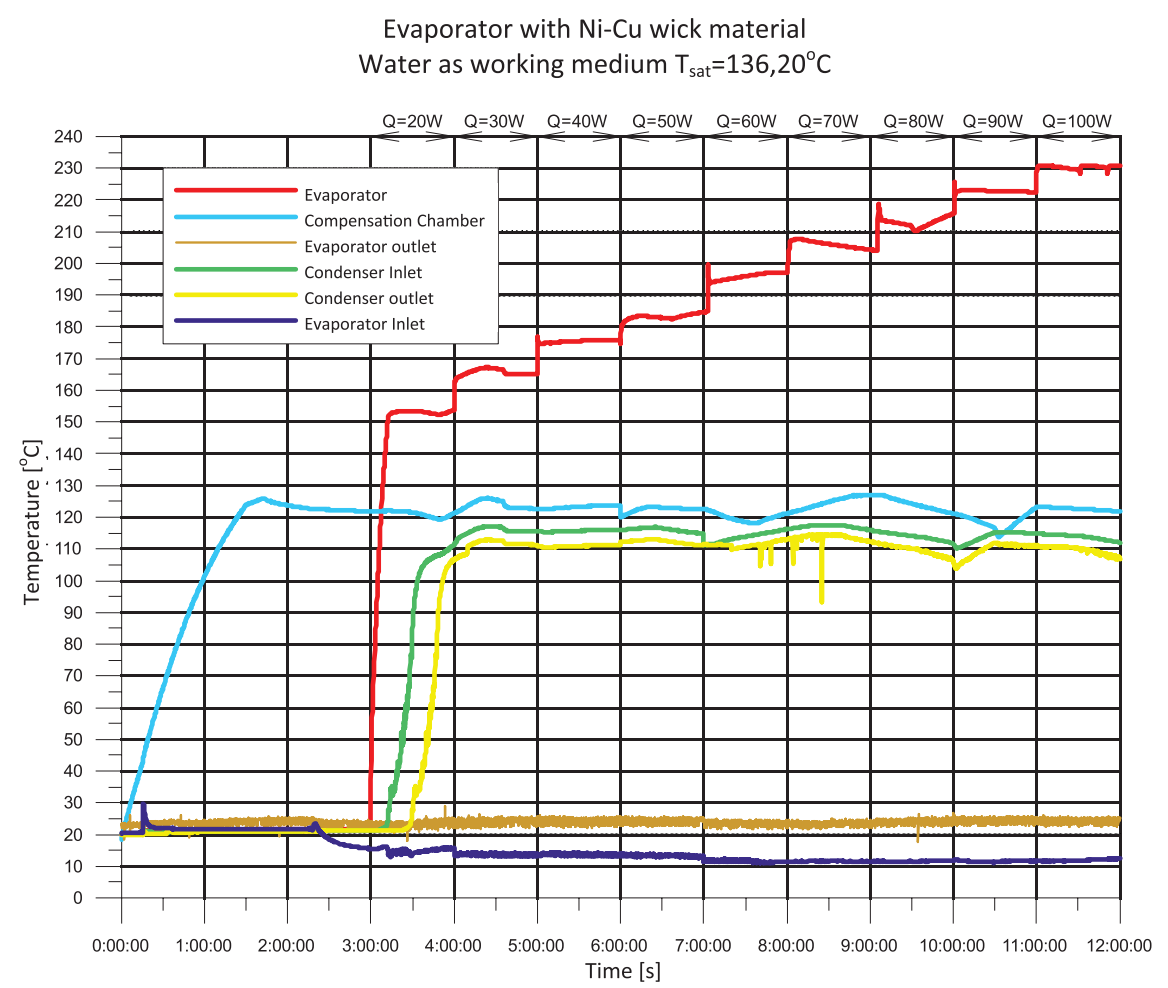

Fig. 6. The effect of heat flux on temperature distribution, for water as working medium and evaporator filled with Ni-Cu wick material

on the outer wall of the vapour transport tube. Consequently, the measurement was burdened with some error resulting from conductive heat transfer through the tube wall and heat loss to the environment.

The evaporator temperature was measured on the outer evaporator wall by the measuring element (thermocouple) placed under the heater. The temperature increased sequentially, as a response to the increase of the delivered thermal power. The initial thermal power delivered to the system was $20 \mathrm{~W}$ and then, after each hour its value was gradually increased by $10 \mathrm{~W}$ until it reached $100 \mathrm{~W}$. When this final level was reached, the temperature in the evaporator

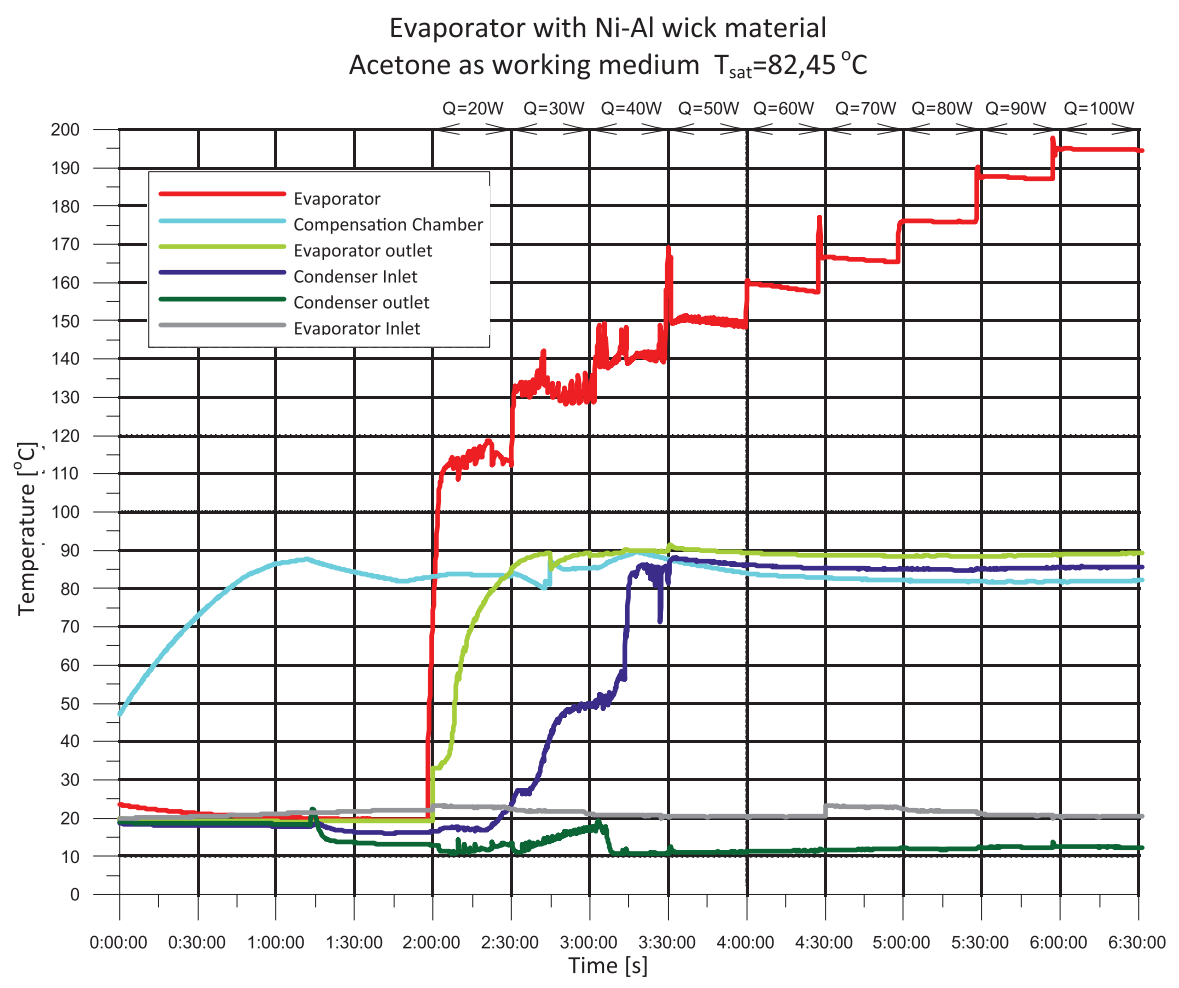

Fig. 7. The effect of heat flux on temperature distribution, for acetone as working medium and evaporator filled with Ni-Al wick material 


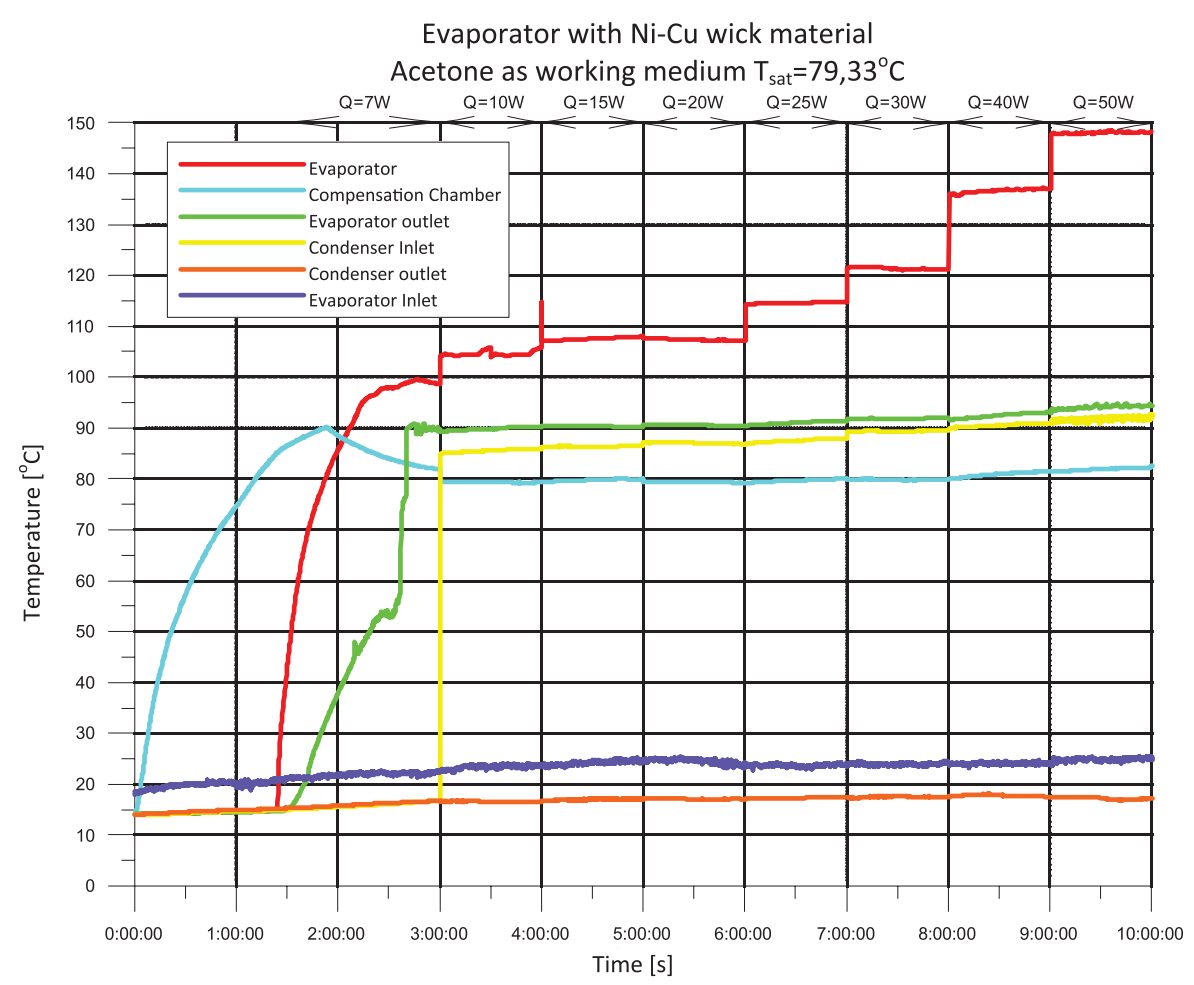

Fig. 8. The effect of heat flux on temperature distributions, for acetone as working medium and evaporator filled with Ni-Cu wick material.

stabilised at the level of about $230^{\circ} \mathrm{C}$ and power delivery was not increased any longer. The measurement was terminated.

The analysis of temperature distribution as function of the delivered heat flux, for acetone as working medium and the evaporator filled with porous $\mathrm{Ni}-\mathrm{Al}$ wick material is shown in Fig. 7, while for the evaporator filled with porous $\mathrm{Ni}-\mathrm{Cu}$ wick material it is given in Fig. 8

The installation with the evaporator filled with porous $\mathrm{Ni}-\mathrm{Al}$ wick material was prepared for operation (heated) during 2 hours, and the entire measuring session lasted 6,5 hours. The time of preparing the installation for operation (heating) was chosen individually for each installation using the trial and error method. As a consequence, compared to the previous test with water and the evaporator filled with $\mathrm{Ni}-\mathrm{Cu}$ wick material, the preparation time was shortened by one hour, to shorten the total time of a single measuring session. For the first two hours, the compensation reservoir was heated with constant heat flux until its temperature stabilised at around $80^{\circ} \mathrm{C}$ and the pressure in the loop reached an approximate level of 2,3 bar (corresponding to the saturation pressure of acetone in the temperature of $80^{\circ} \mathrm{C}$ ). As stated by Tomlinson [13], in typical CPL installations filled with acetone as working medium the temperature in the compensation reservoir should stabilise at the level of about $80 \mathrm{oC}$, before the evaporator heating can start.

The installation with the evaporator filled with porous $\mathrm{Ni}-\mathrm{Cu}$ wick material was heated (prepared) for 1,5 hour (until local parameters stabilised), and the entire measuring session lasted 10 hours. As already mentioned, the preparation (heating) time for each installation was different, as determined experimentally in the trial and error tests.
The installation with porous $\mathrm{Ni}$-Al wick material was heated using the heat flux the initial value of which was $20 \mathrm{~W}$ and then, after each half-hour it was gradually increased by $10 \mathrm{~W}$ until the final, maximal level of $100 \mathrm{~W}$ was reached. The installation with porous $\mathrm{Ni}$ - $\mathrm{Cu}$ wick material was heated using the heat flux the initial value of which was $7 \mathrm{~W}$ and then, after each hour it was gradually increased by $5 \mathrm{~W}$ until the final, maximal level of $50 \mathrm{~W}$ was reached. The maximal power used for heating the evaporator in this installation differed from those in other installations, as this system was equipped with a heater connected to the laboratory power supply the maximal power of which was $50 \mathrm{~W}$. As can be seen in Fig. 8, the flow (motion) of the working medium was only observed when the delivered thermal power equalled $30 \mathrm{~W}$. This motion manifested itself as the temperature increase in the vapour transport line, with simultaneous temperature decrease in the liquid transport line. Moreover, the flow of working medium was observed in the visualisation window and in pressure difference values recorded by the differential pressure transmitter. When the thermal power of $20 \mathrm{~W}$ was delivered, the flow was not observed and the temperature increase at evaporator outlet resulted from heating the evaporator by the heater (heat conduction). During the entire measuring session, the temperature in the compensation reservoir was kept at the approximate level of $80^{\circ} \mathrm{C}$. At the end of the session, i.e. for thermal power equal to $100 \mathrm{~W}$, the temperature on the heater exceeded $190^{\circ} \mathrm{C}$, but the pressure inside the installation was equal to the saturation pressure of about 2,15 bar, which corresponded to the saturation temperature of $82,45^{\circ} \mathrm{C}$. After delivering $100 \mathrm{~W}$ of thermal power to the evaporator, the temperature inside the evaporator stabilised 
at the approximate level of $195^{\circ} \mathrm{C}$ and the measurement was terminated.

In the installation with the evaporator filled with porous $\mathrm{Ni}$-Cu wick material, the flow of working medium was already observed when the delivered heat flux was equal to $7 \mathrm{~W}$. After starting the evaporator heating, the temperature in the vapour line increased and the flow was observed in the visualisation window. At the beginning of the measuring session, i.e. at $7 \mathrm{~W}$, the temperature on the evaporator surface (i.e. on the heater) was about $100^{\circ} \mathrm{C}$, while at the end of measuring session, at $50 \mathrm{~W}$, it reached approximately $150^{\circ} \mathrm{C}$. After the temperature stabilised at this level, the measurement was terminated.

\section{COMPARING RESULTS OF CALCULATIONS WITH THE EXPERIMENT}

\section{MASS FLOW RATE}

Figure 9 compares the calculated and experimentally recorded mass flow rate values as a function of the delivered heat (heater power) for the evaporator filled with porous $\mathrm{Ni}-\mathrm{Cu}$ wick material and water as working medium. The presented diagram shows that the maximal mass flow rate measured in the installation with water as working medium is $0,067[\mathrm{~g} / \mathrm{s}]$, while the theoretical value calculated for the same heater power is $0,055[\mathrm{~g} / \mathrm{s}]$. For the heater power equal to $90 \mathrm{~W}$ the values obtained from the mathematical model and from the experiment are comparable. In cases of larger powers delivered to the evaporator we can observe the twophase flow in the system. In those cases the flow losses should be calculated based on the so-called two-phase multiplier. For smaller contents of vapour in the flow this multiplier takes values from within 2 to 4 . Taking this fact into account in the calculations would lead to better convergence between the calculated results and those recorded experimentally.

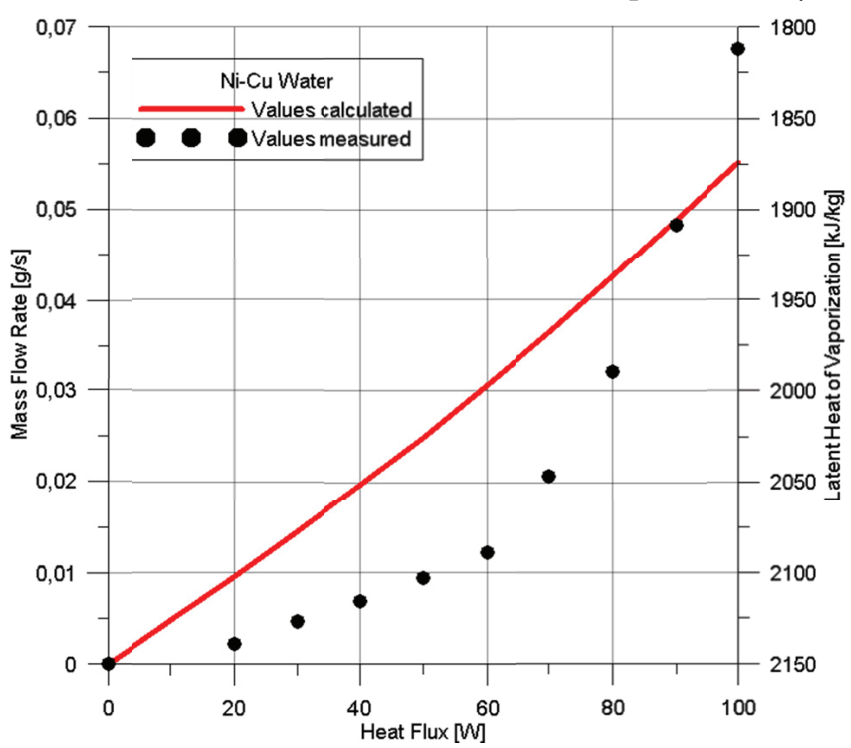

Fig. 9. Mass flow rate of water as working medium in the installation with evaporator filled with porous $\mathrm{Ni}-\mathrm{Cu}$ wick material vs. heat flux.
Figure 10 compares the calculated and experimentally recorded mass flow rate values as a function of the delivered heat (heater power) for the evaporator filled with porous $\mathrm{Ni}-\mathrm{Cu}$ wick material and acetone as working medium. The presented diagram shows that the maximal mass flow rate measured in the installation with acetone as working medium is $0,08[\mathrm{~g} / \mathrm{s}]$, while the theoretical value calculated for the same heater power is 0,015 [g/s].

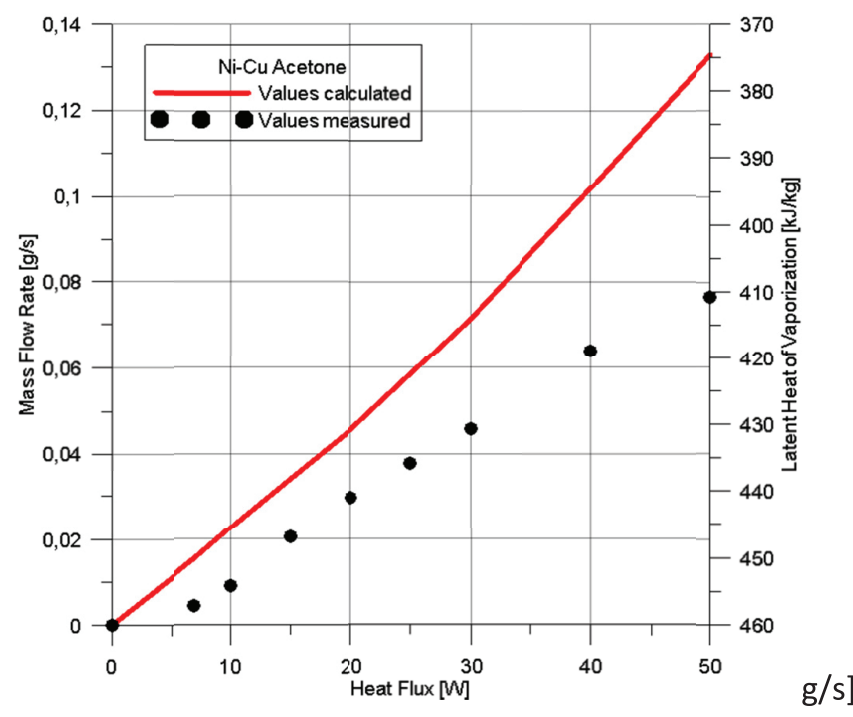

Fig. 10. Mass flow rate of acetone as working medium in the installation with evaporator filled with porous $\mathrm{Ni}$-Cu wick material vs. heat flux. 0,4

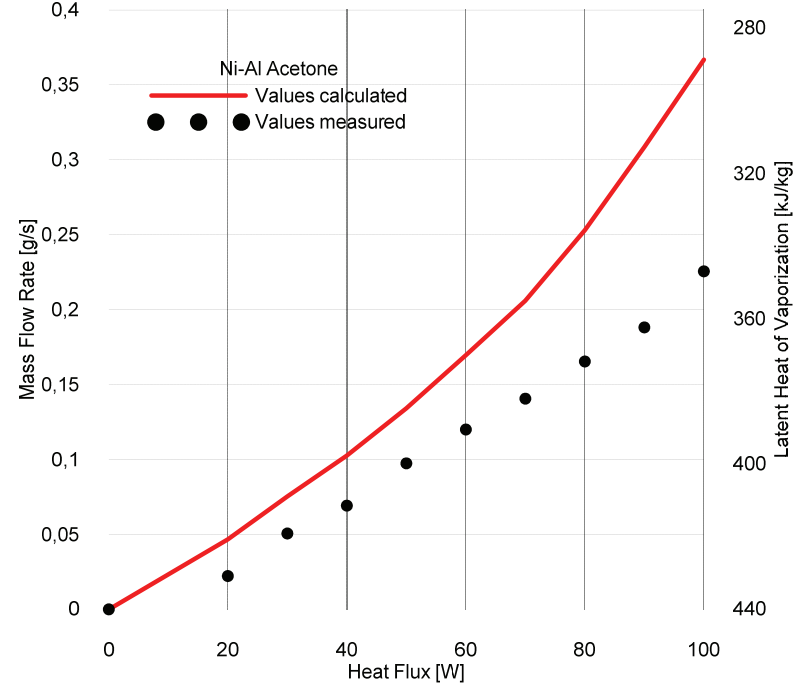

Fig. 11. Mass flow rate of acetone as working medium in the installation with evaporator filled with porous $\mathrm{Ni}$-Al wick material vs. heat flux.

Figure 11 compares the calculated and experimentally recorded mass flow rate values as a function of the delivered heat (heater power) for the evaporator filled with porous $\mathrm{Ni}$-Al wick material and acetone as working medium. The presented diagram shows that the maximal mass flow rate measured in the installation with acetone as working medium is $0,25[\mathrm{~g} / \mathrm{s}]$, while the theoretical value calculated for the same heater power is $0,35[\mathrm{~g} / \mathrm{s}]$. 
Taking into account the accuracy of the differential pressure transducer used for measuring pressure differences $( \pm 0,05 \mathrm{kPa})$ and the loss of heat dissipated to the environment, we can state that for installations with acetone as working medium the applied in-house mathematical model well predicts the values recorded in the experiment.

\section{CONCLUSIONS}

CPL is an effective device for passive transport of heat over relatively large distances. Its basic advantages refer to the absence of external circulation pump (no electric power consumption), the absence of disturbances, maintenance-free operation (no moving parts), and wide range of adjustment and control of operating temperatures in the system. Among other places, CPL can be widely used in military industry for heat collection from devices which are prone to high temperatures.

The article presents the results of experimental tests which aimed at determining abilities to collect in a passive way the heat from precise electronic devices, at heat power generation ranging up to $100 \mathrm{~W}$, which is the value of heat generated by a medium-power radio communication device, and transport it over a distance of about $0,5 \mathrm{~m}$. Further research plans in this area include enlargement of heat fluxes and heat transport distances.

\section{BIBLIOGRAPHY}

1. Mikielewicz D., Szymański P., Błauciak K., Wajs J., Mikielewicz J., Ihnatowicz E., "The new concept of capillary forces aided evaporator for application in domestic organic Rankine cycle" Heat Pipe Science and Technology. - Vol. 1, Iss.4, 359-373, 2010;

2. Mikielewicz D., Szymański P., „Heat pipe with circulating loop as the device for heat recovery (in Polish)" Technika Chłodnicza i Klimatyzacyjna, 6-7, 298-306, 2011;

3. Szymański P., Mikielewicz D., "Experimental tests of the capillary pumping cycle (in Polish)” Technika Chłodnicza i Klimatyzacyjna, 8-9, 321 - 326, 2014;

4. Maydanik Yu. F., "Loop Heat Pipes", Applied Thermal Engineering, 25, (635-657), 2005;

5. Joung W., Hwang H., Lee J., „Experimental study on the operating characteristics of a capillary pumped loop with a flat evaporator" International Journal of Heat and Mass Transfer53, 268-275, 2010;

6. Wang C., Leu T., Lai T., "Micro capillary pumped loop system for a cooling high power device" Experimental Thermal and Fluid Science 32, 1090-1095,2008;

7. Bizzo E., Nogoseke M., "Capillary pumping system for solar heating application" Applied Thermal Engineering 23, 1153-1165,2003;

8. Jung J. et al., "A capillary pumped loop with microcone shaped capillary structure for cooling electronic devices". Journal of Micromechanics and Microengineering, 18, 2008;

9. Chen P., Lin W., "The application of capillary pumped loop for cooling of electronic components", Applied Thermal Engineering 21,1739-1754, 2001;

10. Ku J., "Overview of Capillary Pumped Loop Technology" 1993 ASME National Heat Transfer Conference, Atlanta, GA, 1993;

11. Nikitkin M., Cullimore B.,"CPL and LHP Technologies: What are the Differences, What are the Similarities?" $28^{\text {th }}$ International Conference on Environmental Systems Danvers, Massachusetts, July 13-16, 1998;

12. Kaya T., and Hoang, T. T., "Mathematical Modeling of Loop Heat Pipes" $37^{\text {th }}$ AIAA Aerospace Science Meeting and Exhibit, January 11-14, Reno, Nevada, USA, 1999;

13. Tomlinson B. J. "Steady state analysis of a capillary pumped loop”, Thesis (M.S.)--University of Texas at El Paso, 1997;

\section{CONTACT WITH THE AUTHOR}

Paweł Szymański

Gdańsk University of Technology

11/12 Narutowicza St. 80 - 233 Gdańsk

Poland 